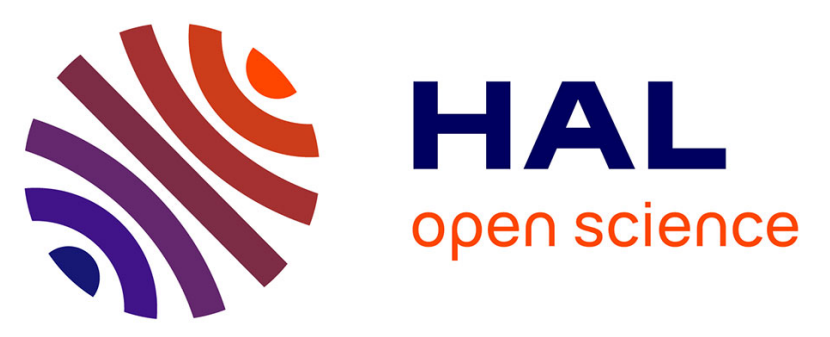

\title{
Rectal and Urethro-Vesical Subregions for Toxicity Prediction After Prostate Cancer Radiation Therapy: Validation of Voxel-Based Models in an Independent Population
}

Eugenia Mylona, Martin Ebert, Angela Kennedy, David Joseph, James

Denham, Allison Steigler, Stéphane Supiot, Oscar Acosta, Renaud de

Crevoisier

\section{- To cite this version:}

Eugenia Mylona, Martin Ebert, Angela Kennedy, David Joseph, James Denham, et al.. Rectal and Urethro-Vesical Subregions for Toxicity Prediction After Prostate Cancer Radiation Therapy: Validation of Voxel-Based Models in an Independent Population. International Journal of Radiation Oncology, Biology, Physics, 2020, S0360-3016 (20), pp.31417-6. 10.1016/j.ijrobp.2020.07.019 . hal02929469

\author{
HAL Id: hal-02929469 \\ https://hal.science/hal-02929469
}

Submitted on 22 Oct 2020

HAL is a multi-disciplinary open access archive for the deposit and dissemination of scientific research documents, whether they are published or not. The documents may come from teaching and research institutions in France or abroad, or from public or private research centers.
L'archive ouverte pluridisciplinaire HAL, est destinée au dépôt et à la diffusion de documents scientifiques de niveau recherche, publiés ou non, émanant des établissements d'enseignement et de recherche français ou étrangers, des laboratoires publics ou privés. 


\section{Rectal and Urethro-vesical Subregions for Toxicity Prediction After Prostate Cancer Radiotherapy: validation of voxel-based models in an independent population}

Eugenia Mylona ${ }^{1, *}$, Martin Ebert ${ }^{2,3,4}$, Angel Kennedy², David Joseph ${ }^{4}$, James Denham ${ }^{5}$, Allison Steigler $^{6}$, Stephane Supiot $^{7}$, Oscar Acosta $^{1}$, Renaud de Crevoisier $^{1}$

\footnotetext{
${ }^{1}$ Univ Rennes, CLCC Eugène Marquis, INSERM, LTSI-UMR 1099, F-35000, Rennes, France.

${ }^{2}$ Department of Radiation Oncology, Sir Charles Gairdner Hospital, Perth, Australia.

${ }^{3}$ School of Physics, Mathematics and Computing, University of Western Australia, Perth, Australia

${ }^{4} 5$ D Clinics, Perth, Australia

${ }^{5}$ School of Medicine and Public Health, University of Newcastle, Australia.

${ }^{6}$ Prostate Cancer Trials Group, Faculty of Health, University of Newcastle, Callaghan, Australia.

${ }^{7}$ Department of Radiation Oncology, Centre Georges François Leclerc, Dijon, France.
}

Short running title: External validation of GI and GU subregions

\footnotetext{
*Corresponding author

Email address: eugenia.mylona@inserm.fr
} 
Research data are stored in an institutional repository and will be shared upon request to the corresponding author.

Disclosures: None.

Funding: This work was supported by the French Institut National du Cancer, a French government grant (through the CominLabs excellence laboratory and managed by the National Research Agency in the "Investing for the Future" program, under reference ANR-10-LABX-0701) and the PHC FASIC mobility grant. The PROFIT study was funded by Programme Hospitalier de Recherche Clinique, French Ministry of Health. We also acknowledge funding from the Australian National Health and Medical Research Council (grants 300705, 455521, 1006447, 1077788), the Hunter Medical Research Institute, the Health Research Council (New Zealand), the University of Newcastle, the Calvary Mater Newcastle, Abbott Laboratories and Novartis Pharmaceuticals. We gratefully acknowledge the support of the Sir Charles Gairdner Hospital.

Author responsible for statistical analysis: Eugenia Mylona

eugenia.mylona@inserm.fr 


\section{Abstract}

Purpose/Objectives: Recent voxel-based studies have shown that the dose to specific rectal and urethro-vesical subregions is predictive of toxicities, following prostate cancer IMRT. The objective of this study was to validate the discriminatory power of these subregions with respect to the whole organs, in a large independent population.

Material/Methods: The validation cohort consisted of 450 patients, from the XXX(BLIND) trial, treated with 3D-CRT at 66-74 Gy. Previous voxel-based analyses identified an infero-anterior rectal subregion as predictive of rectal bleeding and five subregions in the urethra and the posterior and superior part of the bladder as predictive of urinary incontinence, dysuria, retention and hematuria. In the validation cohort, these subregions were segmented in each patient's anatomy. DVHs of the whole organs and the six subregions were compared bin-wise between patients with and without toxicities. The discriminatory power of DVHs for grade $\geq 2$ toxicity endpoints was assessed using the area under the ROC curve (AUC).

Results: Subregion DVHs were significantly different between patients with and without toxicities for late rectal bleeding (V44-V74), acute urinary incontinence (V68-V72), late dysuria (V56-V68) and late retention (V14-V64). The dose to the rectal subregion and the whole rectum

were equally predictive of rectal bleeding ( $\mathrm{V} 68$; AUC $=0.61)$. The doses to three out of the five urethro-vesical subregions were found to be more predictive than the dose to the whole bladder: in the urethra for acute incontinence $(\mathrm{V} 71 ; \mathrm{AUC}=0.69$ versus $\mathrm{V71}$; $\mathrm{AUC}=0.66)$, in the posterior part of the bladder for late dysuria ( $665 ; \mathrm{AUC}=0.66$ vs $\mathrm{V} 68 ; \mathrm{AUC}=0.59$ ) and late retention (V39;AUC=0.74 vs no significant AUC).

Conclusion: Three subregions located in the urethra and the bladder were successfully validated as more predictive of urinary toxicity than the whole bladder, for urinary incontinence, retention and dysuria. Sparing in particular the posterior part of the bladder in treatment planning may reduce the risk of late urinary retention. 


\section{Introduction}

Gastrointestinal (GI) and genitourinary (GU) toxicities following prostate cancer radiotherapy are the most common radiation-induced complications, with 5-year grade $\geq 2$ rates ranging from 6 to $38 \%$ and from 10 to $46 \%$, respectively (1-3). Traditionally, dose-volume histogram (DVH) parameters extracted from the whole organ-at-risk are used to analyze the dose-effect relationships. Recently, novel approaches, commonly referred as voxel-based methods, enabled the analysis of the entire 3D dose distribution at fine spatial scales, providing evidence of variable intra-organ radiosensitivity (4-7). Such approaches rely on deformable image registration to align patient anatomies and map dose distributions to a common space of reference, enabling voxel-by-voxel dosimetric comparisons between patients with/without toxicity (8).

Two studies, aiming at identifying organ subregions predictive of GI and GU toxicities, applied voxel-based analyses on a dataset of 254 patients with localized prostate cancer, treated with IMRT/IGRT at total dose 78/80Gy, from two prospective trials $(9,10)$. A subregion located in the inferior-anterior hemi-anorectum predictive of late rectal bleeding (5) and five urethro-vesical subregions predictive of grade $\geq 1 \mathrm{GU}$ toxicities (6) were identified. However, the predictive value of these subregions was assessed in the same cohort used for model development (herein called "development" cohort). In order to translate these findings into clinical practice, the improvement in toxicity prediction when considering these subregions, compared to the whole organ, needs to be demonstrated in independent populations. In addition, the superiority of the subregions should be confirmed for more clinically relevant toxicity events (grade $\geq 2$ ).

The objective of this study was, thus, to validate in a large independent population (herein called "validation" cohort), the predictive value of these rectal and urethro-vesical subregions for grade $\geq 2 \mathrm{GI}$ and GU toxicity prediction.

\section{MATERIALS AND MethodS}

\section{VALIDATION COHORT CHARACTERISTICS}

The validation cohort comprises 450 patients from the prospective XXX(BLIND) trial, treated with 3DCRT at a total dose of 66,70 or 74 Gy (2Gy/fraction) (11). This trial is registered with 
number XXX(BLIND) in ClinicalTrials.gov. Patient and treatment characteristics are summarized in Table A1 (Supplementary material). The median follow-up was 72 months. Rectal and urinary toxicities were assessed using the LENT/SOMA and IPSS systems. Grade $\geq 2$ toxicity rates were $23 \%$ for rectal bleeding and ranged from 2 to $16 \%$ for urinary toxicities.

The radiation treatment technique and organ dose constraints for the development and validation cohorts are described in Supplementary material (Appendix A). More details can also be found in previous publications $(5,6,11-14)$.

Figure 1 shows the workflow of the study.

\section{DEFINITION OF RECTAL AND URINARY TOXICITY SUBREGIONS IN THE VALIDATION COHORT}

Concerning rectal toxicity, a voxel-wise analysis of the dose distributions in the rectum allowed the identification of a generic, geometrically-defined subregion, predictive of 3-year rectal bleeding (grade $\geq 1$ and grade $\geq 2$ ) (Figure 1A) (5). In the validation cohort, dedicated software was used to automatically segment this subregion in each individual's anatomy (Figure 1B).

Concerning urinary toxicity, a voxel-wise analysis of the dose distribution in the bladder and the urethra allowed the identification of five subregions predictive of acute retention and incontinence and late retention, dysuria and hematuria (Figure A1) (6). In the validation cohort, the prostatic urethra was, first, segmented on planning CT images using a multi-atlas-based segmentation algorithm (15). Then, the five urethro-vesical subregions, defined in a templatepatient, were non-rigidly registered to each individual's anatomy. Registration accuracy was assessed using the Dice score $(0.88 \pm 0.04$ for the prostate and $0.92 \pm 0.06$ for the bladder).

Figure 2A displays the six subregions identified in the development cohort.

\section{STATISTICAL ANALYSIS}

All the analyses were performed using the physical dose. DVHs were computed for the rectum, the bladder, the urethra and the six subregions. Wilcoxon test was performed bin-wise to compare patients with and without grade $\geq 2$ toxicities. For each endpoint studied, patients with relevant baseline symptoms were excluded from the analysis (Supplementary material; Table A1). The discriminatory power of the DVHs was assessed in univariate analysis using logistic regression and the area under the ROC curve (AUC) for acute toxicities while Cox regression and the timedependent AUC (tAUC) (16) were used for late toxicities. Bootstrapping with 1000 replicates was performed to determine AUC, t-AUC, and 95\% confidence intervals. 


\section{RESULTS}

Figure 3 displays organ and subregion DVHs for patients with and without toxicities. Considering the subregions, significant differences were found for late rectal bleeding (V44-V74), acute urinary incontinence (V68-V72), late dysuria (V56-V68) and late retention (V14-V64). Considering the whole organs, significant differences were found for late rectal bleeding (V63V74), acute urinary incontinence (V67-V72) and late hematuria (V65-V70).

Table 1B shows the discriminatory power of the DVHs for the bladder, the rectum, the urethra and the six subregions. The DVHs of the whole rectum and the rectal subregion demonstrated equal discriminatory power (V68; tAUC $=0.61[95 \% \mathrm{CI}$ : 0.55-0.66]). The doses to three urethro-vesical subregions were predictive for grade $\geq 2$ acute incontinence (V71; AUC=0.69 [95\%CI:0.60-0.80]), late retention (V39; tAUC=0.74[95\%CI:0.62-0.87]) and late dysuria (V65; tAUC=0.66[95\%CI: $0.59-0.73])$. The dose to the whole urethra was predictive only for grade $\geq 2$ acute incontinence (V71; AUC $=0.68$ [95\%CI:0.60-0.79]). The dose to the whole bladder was predictive for acute incontinence (V71; AUC=0.66 [95\%CI:0.56-0.75]) and late dysuria (V68; tAUC=0.59 [95\%CI:0.50-0.69]). Figure 4 shows the discriminatory ability of the DVHs (bin-wise) for the subregions and the whole organs.

Figure $2 \mathrm{~B}$ displays the three subregions confirmed as more predictive than the whole organs in the validation cohort.

\section{DISCUSSION}

Voxel-wise analysis is a novel approach allowing the identification of subregions in organsat-risk potentially predictive of toxicity. External validation of previously developed voxel-based spatial models $(5,6)$ was performed, confirming that symptom-specific local dose-effect patterns exist in the urethra for acute urinary incontinence and in the bladder for late retention and dysuria. By considering the dose to these subregions, instead of the whole bladder, the ability of the models to discriminate patients with and without grade $\geq 2$ toxicities was improved.

In practice, sparing all three subregions in treatment planning, although promising for reducing multiple urinary side-effects, may not always be feasible. In this context, some structures can be considered as more important than others. Even if subregions have been validated for clinically 
relevant toxicity endpoints (grade $\geq 2$ ), late symptoms, namely retention and dysuria, are expected to affect patients' quality of life more severely because of their prolonged duration. Late retention, in particular, has higher prevalence in both populations and the corresponding predictive model exhibits superior discrimination. Thus, sparing the posterior part of the bladder (above the trigone) corresponding to late retention, should be prioritized in treatment planning. Apart from the bladder, current findings also indicate a dose-effect relationship in the entire urethral volume for acute urinary incontinence. Even so, reducing the dose to the urethra requires more advanced treatment techniques, such as urethra-sparing stereotactic body radiation therapy (US-SBRT) (17).

On the other hand, two bladder subregions previously identified as predictive for acute retention and late hematuria, as well as the subregion in the rectum associated with rectal bleeding, were not confirmed in the validation cohort as more predictive than the whole organ. Differences between population settings (Tables A1), including the treatment technique, toxicity rates and geographic/temporal aspects, raise questions about a potential "cohort-effect" when performing population-based analyses (18). Noteworthy differences include: significant differences in bladder volume (Table A1), due to the different bladder filling protocols applied in the two populations; higher toxicity rates in the validation cohort ( see Table 1A). For instance, rates of grade $\geq 2$ rectal bleeding were four times higher than in the development cohort, possibly due to the use of 3DCRT (1). Overall, these differences may have implications on the generalizability of some subregions.

A limitation of this work is that the statistical DVH-based predictive models, obtained from the development cohort, could not be directly applied to the validation cohort as a part of the external validation process (19). This is due to the differences in the prescribed doses between the two populations. Moreover, the validation cohort was treated with 3D-CRT with prescribed doses $\leq 74 \mathrm{~Gy}$, which is not representative of the current clinical practices, where higher and conformal doses are delivered to the tumor. Another weakness arises from the consideration of the planning dose distribution which may differ from the actual delivered dose due to intra- and inter-fraction anatomical variations $(20,21)$. Finally, clinical and biological parameters were not tested in a multivariate setting.

In conclusion, the present study validates three bladder and urethra subregions as more predictive of urinary toxicity, than the whole bladder. These findings highlight the need to go beyond the whole organ-based dosimetric constraints, towards optimized, patient-tailored suborgan constraints. Clinical trials, however, are needed to demonstrate that these optimized planning 
strategies are able to significantly reduce urinary toxicity in the case of prostate cancer radiotherapy. 


\section{REFERENCES}

1. Wortel RC, Incrocci L, Pos FJ, et al. Late Side Effects After Image Guided Intensity Modulated Radiation Therapy Compared to 3D-Conformal Radiation Therapy for Prostate Cancer: Results From 2 Prospective Cohorts. Int. J. Radiat. Oncol. Biol. Phys. 2016;95:680-689.

2. Jolnerovski M, Salleron J, Beckendorf V, et al. Intensity-modulated radiation therapy from 70Gy to 80Gy in prostate cancer: six- year outcomes and predictors of late toxicity. Radiat. Oncol. 2017;12:99.

3. Zelefsky MJ, Cowen D, Fuks Z, et al. Long term tolerance of high dose three-dimensional conformal radiotherapy in patients with localized prostate carcinoma. Cancer. 1999;85:24602468.

4. Palma G, Monti S, D’Avino V, et al. A Voxel-Based Approach to Explore Local Dose Differences Associated With Radiation-Induced Lung Damage. Int. J. Radiat. Oncol. Biol. Phys. 2016;96:127-133.

5. Dréan G, Acosta O, Ospina JD, et al. Identification of a rectal subregion highly predictive of rectal bleeding in prostate cancer IMRT. Radiother. Oncol. 2016;119:388-97.

6. Mylona E, Acosta O, Lizee T, et al. Voxel-Based Analysis for Identification of Urethrovesical Subregions Predicting Urinary Toxicity After Prostate Cancer Radiation Therapy. Int. J. Radiat. Oncol. Biol. Phys. 2019;104:343-354.

7. McWilliam A, Kennedy J, Hodgson C, et al. Radiation dose to heart base linked with poorer survival in lung cancer patients. Eur. J. Cancer. 2017;85:106-113.

8. Acosta O, Drean G, Ospina JD, et al. Voxel-based population analysis for correlating local dose and rectal toxicity in prostate cancer radiotherapy. Phys. Med. Biol. 2013;58:2581-95.

9. de Crevoisier R, Bayar MA, Pommier P, et al. Daily Versus Weekly Prostate Cancer Image Guided Radiation Therapy: Phase 3 Multicenter Randomized Trial. Int. J. Radiat. Oncol. Biol. Phys. 2018;102:1420-1429.

10. Catton CN, Lukka H, Gu C-S, et al. Randomized Trial of a Hypofractionated Radiation Regimen for the Treatment of Localized Prostate Cancer. J. Clin. Oncol. 2017;35:1884-1890.

\section{XXX}

12. XXX

13. XXX

14. XXX

15. Acosta O, Mylona E, Le Dain M, et al. Multi-atlas-based segmentation of prostatic urethra from planning CT imaging to quantify dose distribution in prostate cancer radiotherapy.

Radiother. Oncol. 2017;125:492-499. 
16. Chambless LE, Diao G. Estimation of time-dependent area under the ROC curve for longterm risk prediction. Stat. Med. 2006;25:3474-3486.

17. Sato M, Hirose K, Hatayama Y, et al. The Potential of the Urethra-Sparing Intensity Modulated Radiation Therapy for Localized Prostate Cancer for Preventing Genitourinary Toxicity: An Interim Analysis. Int. J. Radiat. Oncol. Biol. Phys. 2018;102:e140.

18. Mylona E, Cicchetti A, Rancati T, et al. Local dose analysis to predict acute and late urinary toxicities after prostate cancer radiotherapy: Assessment of cohort and method effects. Radiother. Oncol. 2020;147:40-49.

19. Moons KGM, Altman DG, Reitsma JB, et al. Transparent reporting of a multivariable prediction model for individual prognosis or diagnosis (TRIPOD): Explanation and elaboration. Ann. Intern. Med. 2015;162:W1-W73.

20. Nassef M, Simon A, Cazoulat G, et al. Quantification of dose uncertainties in cumulated dose estimation compared to planned dose in prostate IMRT. Radiother. Oncol. 2016;119:129-136.

21. Fuchs F, Habl G, Devečka M, et al. Interfraction variation and dosimetric changes during image-guided radiation therapy in prostate cancer patients. Radiat. Oncol. J. 2019;37:127. 


\section{Tables \& Figures}

\begin{tabular}{|c|c|c|c|c|c|c|c|c|}
\hline \multirow{2}{*}{\multicolumn{2}{|c|}{ Symptom }} & \multicolumn{2}{|c|}{ A. Toxicity rates } & \multicolumn{5}{|c|}{ B. Discriminatory power of the DVH (validation cohort) } \\
\hline & & $\begin{array}{l}\text { Development } \\
\text { cohort }\end{array}$ & $\begin{array}{l}\text { Validation } \\
\text { cohort }\end{array}$ & $\begin{array}{l}\text { Anatomical } \\
\text { region }\end{array}$ & $\begin{array}{l}\text { Predictor } \\
\text { (DVH bin)† }\end{array}$ & $p$ value & OR/HR (95\% Cl) & AUC/tAUC \\
\hline \multicolumn{9}{|c|}{ Rectal toxicity } \\
\hline \multirow{2}{*}{\multicolumn{2}{|c|}{$\begin{array}{l}\text { Rectal bleeding } \\
\text { (at 3-years) }\end{array}$}} & \multirow{2}{*}{$6 \%(3-9 \%)$} & \multirow{2}{*}{$\begin{array}{l}23 \%(17- \\
29 \%)\end{array}$} & Whole rectum & V68 & $0.003 * *$ & $1.04(1.01-1.07)$ & $0.61(0.55-0.66)$ \\
\hline & & & & Subregion & V68 & $0.002 * *$ & $1.02(1-1.03)$ & $0.61(0.55-0.66)$ \\
\hline \multicolumn{9}{|c|}{ Urinary toxicity } \\
\hline \multirow{6}{*}{ Acute } & \multirow{3}{*}{ Retention\$ } & \multirow{3}{*}{$19 \%$} & \multirow{3}{*}{$24 \%$} & Whole bladder & V56 & 0.601 & $1.01(0.99-1.02)$ & $0.51(0.38-0.59)$ \\
\hline & & & & Urethra & V74 & 0.451 & $1(0.99-1.01)$ & $0.52(0.46-0.58)$ \\
\hline & & & & Subregion & V57 & 0.128 & $0.98(0.95-1.01)$ & $0.53(0.49-0.61)$ \\
\hline & \multirow{3}{*}{ Incontinence } & \multirow{3}{*}{$0 \%$} & \multirow{3}{*}{$7 \%$} & Whole bladder & V71 & $0.004 * *$ & 1.05 (1.01-1.08) & $0.66(0.56-0.75)$ \\
\hline & & & & Urethra & V71 & $0.011^{*}$ & 1.02 (1.01-1.04) & $0.68(0.60-0.79)$ \\
\hline & & & & Subregion & V71 & $0.010^{*}$ & 1.03 (1.01-1.05) & $0.69(0.60-0.80)$ \\
\hline \multirow{9}{*}{$\begin{array}{l}\text { Late }(5 \\
\text { years) }\end{array}$} & \multirow{3}{*}{ Dysuria } & \multirow{3}{*}{$1 \%(0-2 \%)$} & \multirow{3}{*}{$8 \%(5-11 \%)$} & Whole bladder & V68 & $0.037^{*}$ & $1.03(1-1.06)$ & $0.59(0.50-0.69)$ \\
\hline & & & & Urethra & V70 & 0.137 & $1.05(0.96-1.11)$ & $0.54(0.45-0.63)$ \\
\hline & & & & Subregion & V65 & $0.001^{* *}$ & $1.02(1-1.03)$ & $0.66(0.59-0.73)$ \\
\hline & \multirow{3}{*}{ Retention\$ } & \multirow{3}{*}{$10 \%(5-15 \%)$} & \multirow{3}{*}{$\begin{array}{l}16 \%(9- \\
22 \%)\end{array}$} & Whole bladder & V37 & 0.054 & $1.02(0.99-1.04)$ & $0.59(0.49-0.70)$ \\
\hline & & & & Urethra & V67 & 0.120 & $1.04(0.99-1.08)$ & $0.55(0.50-0.60)$ \\
\hline & & & & Subregion & V39 & $0.009 * *$ & $1.02(1-1.03)$ & $0.74(0.62-0.87)$ \\
\hline & \multirow{3}{*}{$\begin{array}{l}\text { Hematuria } \\
\text { (grade } \geq 1 \text { ) }\end{array}$} & \multirow{3}{*}{$10 \%(6-14 \%)$} & \multirow{3}{*}{$\begin{array}{c}14 \%(11- \\
17 \%)\end{array}$} & Whole bladder & V70 & 0.094 & $1.02(0.99-1.05)$ & $0.56(0.48-0.64)$ \\
\hline & & & & Urethra & V71 & $0.048^{*}$ & $1.01(1-1.02)$ & $0.56(0.5-0.63)$ \\
\hline & & & & Subregion & V48 & 0.261 & $0.97(0.93-1.01)$ & $0.54(0.49-0.58)$ \\
\hline $\begin{array}{l}\text { OR: Odd } \\
\text { the ROC } \\
\text { validati } \\
\text { Questic }\end{array}$ & $\begin{array}{l}\text { ds ratios; HR: } \\
\text { C curve; }+ \text { DVH } \\
\text { on cohort as IP } \\
\text { ons } 1,3,5 \text { and }\end{array}$ & $\begin{array}{l}\text { Hazard ratio; } \mathrm{Cl} \\
\text { bin with the } \mathrm{mo} \\
\text { PSS-O } \geq 11 \text {, wher } \\
6 \text { ). }{ }^{*} \text { p-value } \leq\end{array}$ & $\begin{array}{l}0.05 ;{ }^{* *} \text { p-va } \\
0.0 \text { IPSS }\end{array}$ & $\begin{array}{l}\text { interval; AUC: A } \\
\text { th AUC/tAUC (low } \\
\text { the sum of the sc } \\
\text { alue } \leq 0.01 \text {. }\end{array}$ & cores for the & $\begin{array}{l}\text { he ROC cu } \\
\text { ); } \text { ' Urinar } \\
\text { question }\end{array}$ & $\begin{array}{l}\text { ve; tAUC: time-de } \\
\text { retention grade } \geq \\
\text { expressing an obst }\end{array}$ & $\begin{array}{l}\text { endent area under } \\
\text { was defined in the } \\
\text { ructive urinary effec }\end{array}$ \\
\hline
\end{tabular}

\section{Table 1. Grade $\geq 2$ toxicity rates in the development and validation cohorts (A) and toxicity}

discriminatory power of the whole organs' and subregions' DVHs (B)

(A) Late toxicity rates and $95 \%$ confidence intervals were computed using the Kaplan-Meier method. (B) Logistic and Cox regression were used to compute the discriminatory power of DVHs for acute and late toxicities, respectively. Analysis was performed for grade $\geq 2$ toxicities with the exception of hematuria for which the analysis was performed only for grade $\geq 1$, due to the low number of grade $\geq 2$ events. 


\section{A. Development cohort (previous studies) \\ Voxel-wise analysis and subregion identification}

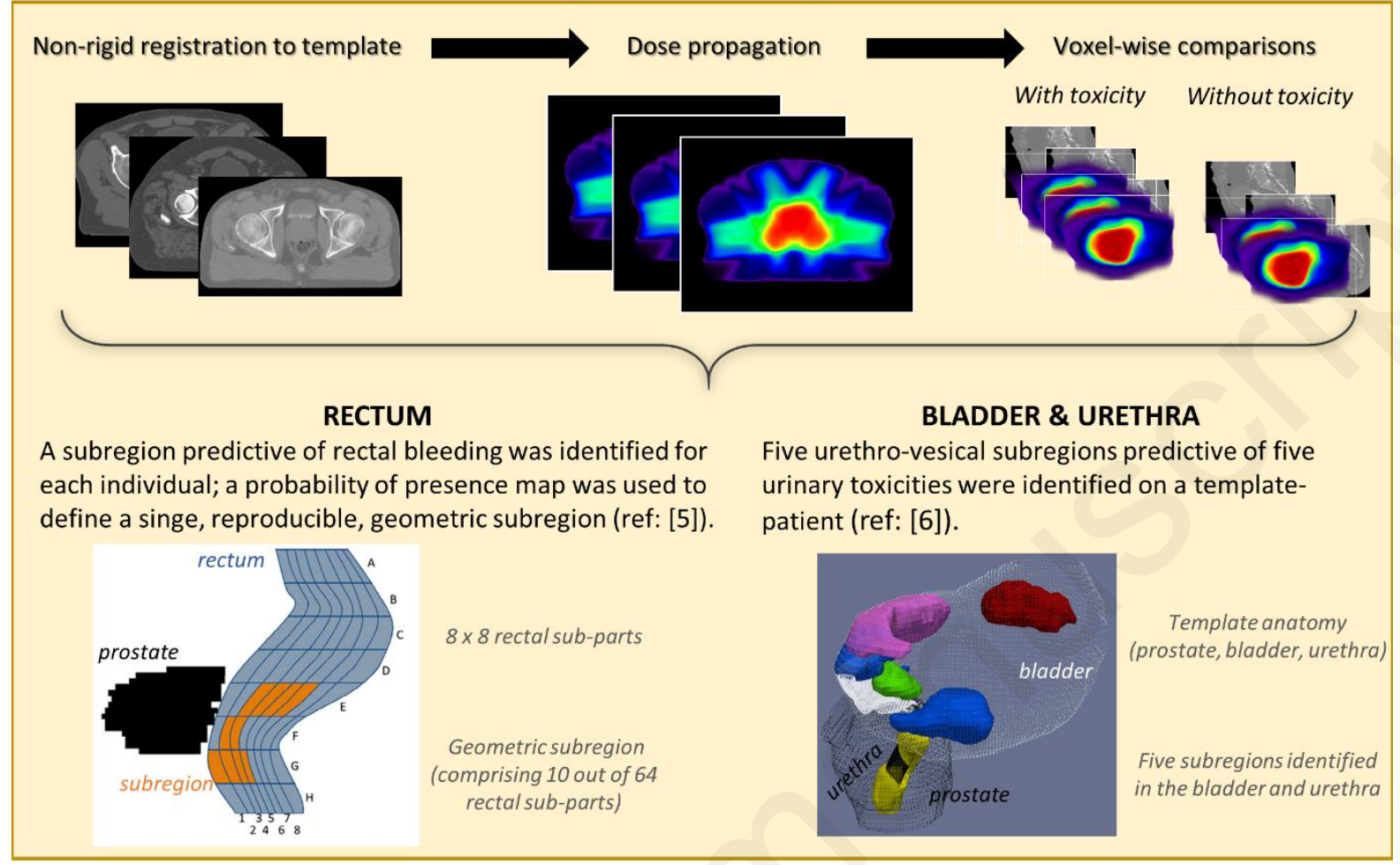

B. Validation cohort (present study)

subregion identification and evaluation of discriminatory power

\section{RECTUM}

First, rectum outlines were redefined according to the anorectum definitions used in the development cohort.

For each individual, the subregion was identified within $8 \times 8$ divided rectum subsections, allowing segmentation without registration.

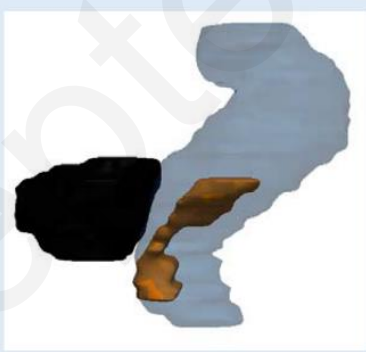

\section{BLADDER \& URETHRA}

For each individual, non-rigid registration to the template-patient was performed, allowing propagation of urethro-vesical subregions to the individual anatomy of each patient.

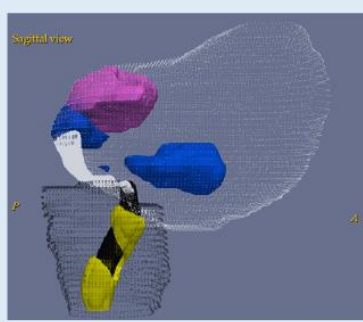

DVH bin-wise comparisons between patients with/without toxicity were performed (Wilcoxon test).
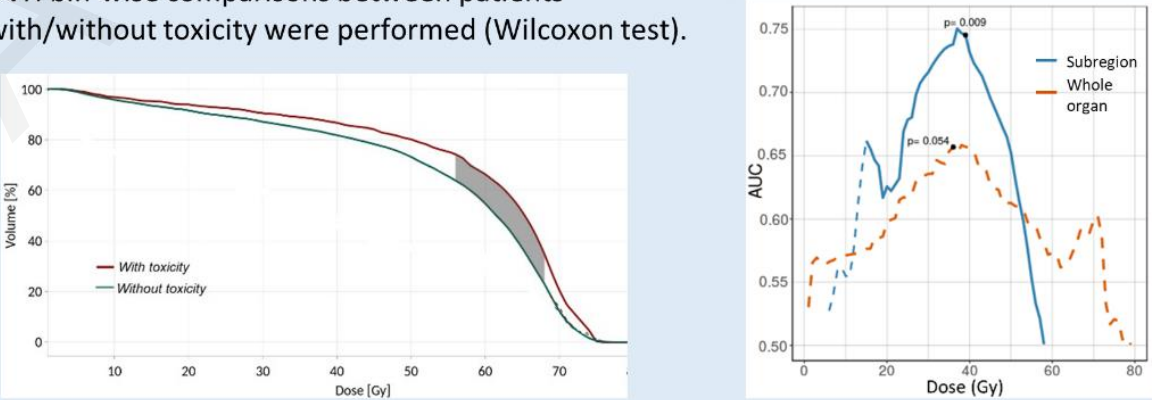

Improvement in the discriminatory power (AUC) of the subregion's DVH was assessed with respect to the whole organ's DVH. 
Figure 1. Study workflow

(A) Rectal and urethro-vesical subregions predictive of GI and GU toxicities, were identified in previous voxel-based studies $(5,6)$. (B) In the present study, these subregions were segmented in a validation cohort and their ability to discriminate patients with/without grade $\geq 2$ toxicities was evaluated. 
A

Subregions identified in the development cohort

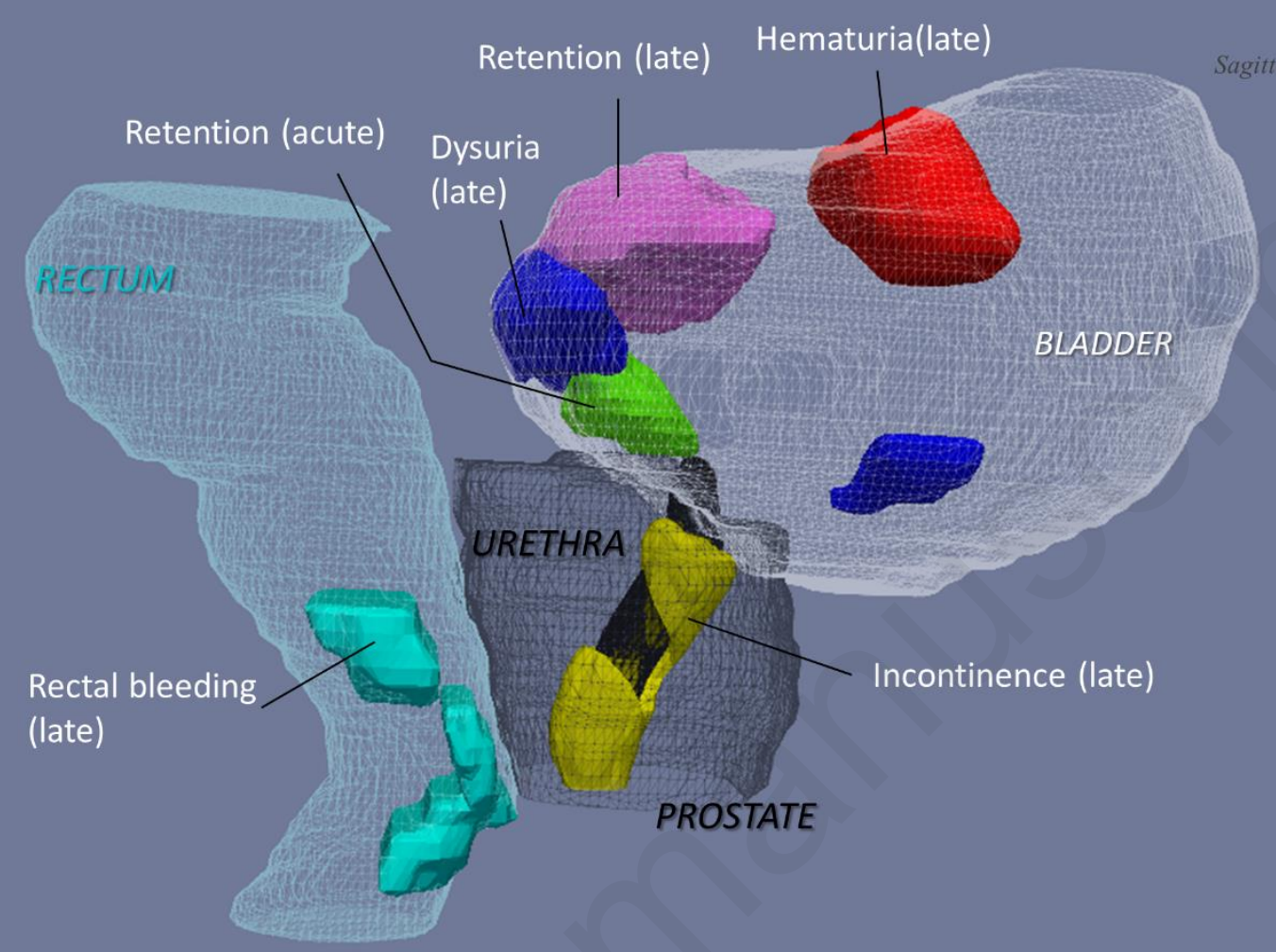

B

\section{Subregions confirmed in the validation cohort}

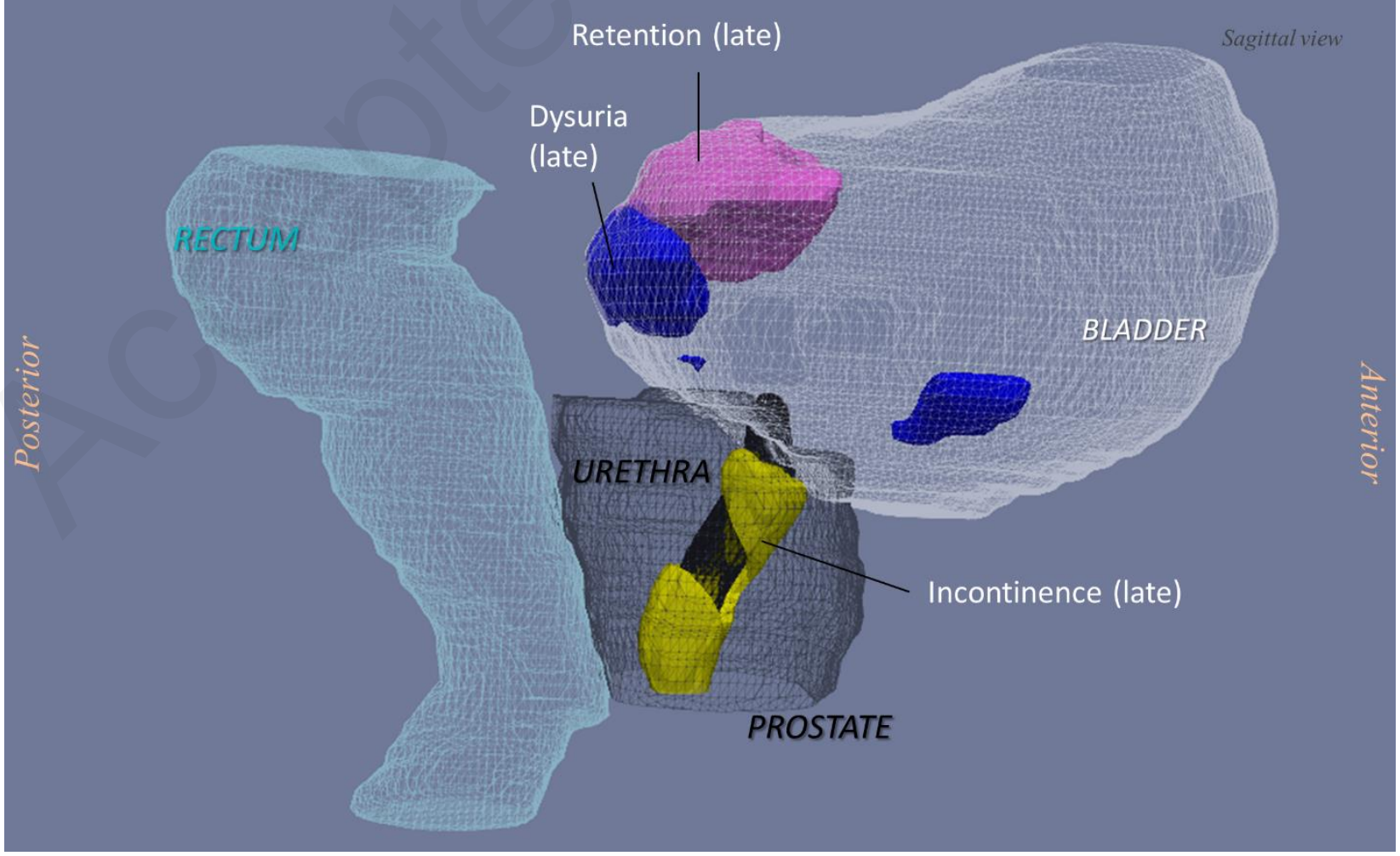


Figure 2. Subregions identified as predictive of GI and GU toxicities in the development cohort (A) and subregions confirmed as predictive in the validation cohort (B)

Three out of six subregions were confirmed as more predictive than the whole organ. All the subregions in the development cohort (A) were identified for grade $\geq 1$ toxicity endpoints. All the subregions confirmed in the validation cohort (B) correspond to grade $\geq 2$ toxicity endpoints. 

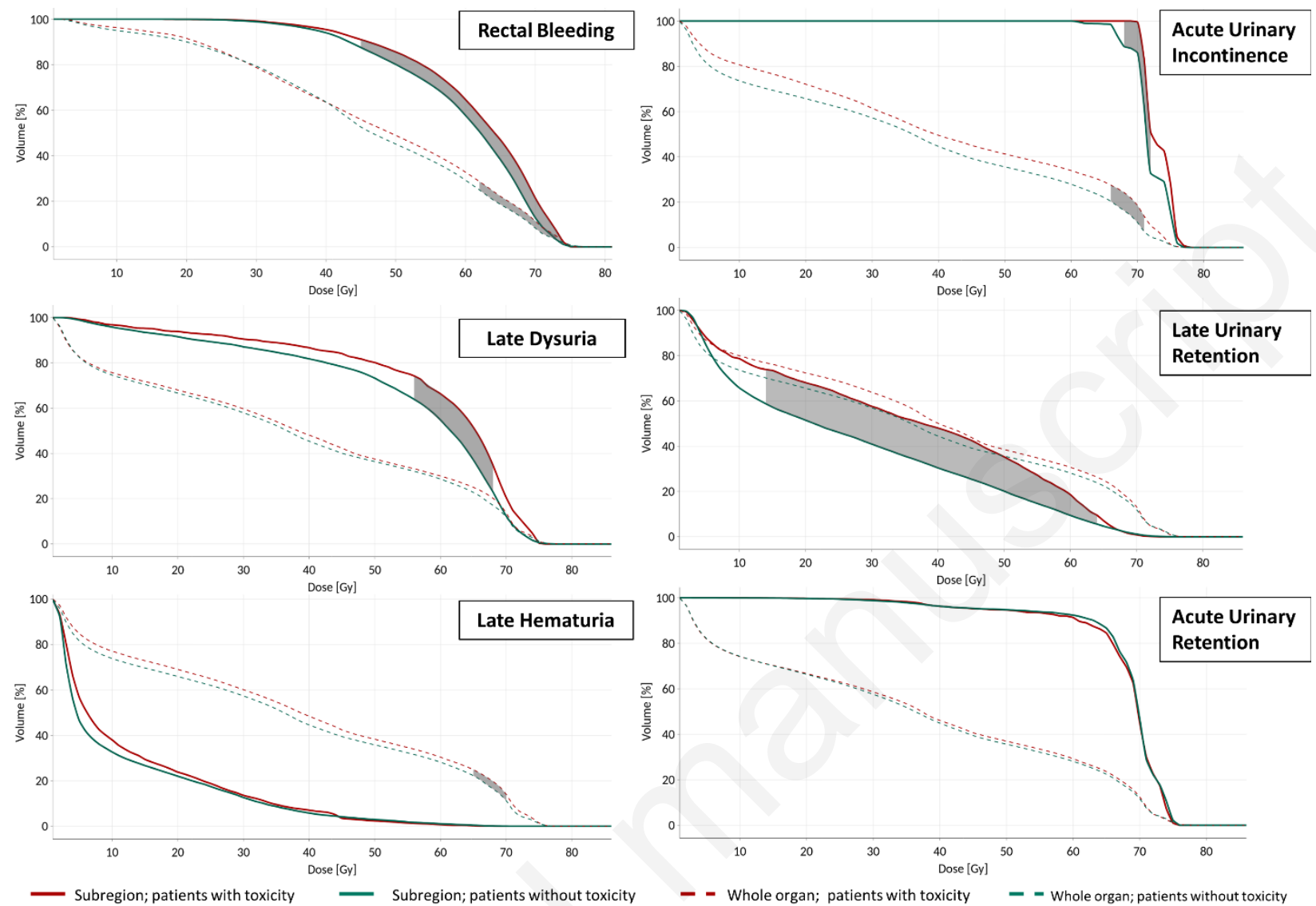

Figure 3. Dose-volume histograms of the subregions and the whole organs for patients with and without toxicities in the validation cohort

Red and green curves represent the average DVHs of the patient with/without toxicity symptoms (grade $\geq 2$ toxicity), respectively. Continuous lines represent the subregions and dash lines the whole organ. The shadowed regions indicate dose bins with significant differences between patients with/without toxicity (Wilcoxon test; $p \leq 0.05$ ). DVHs were computed for grade $\geq 2$ toxicity with the exception of hematuria for which the analysis was performed only for grade $\geq 1$, due to the low number of grade $\geq 2$ events. 

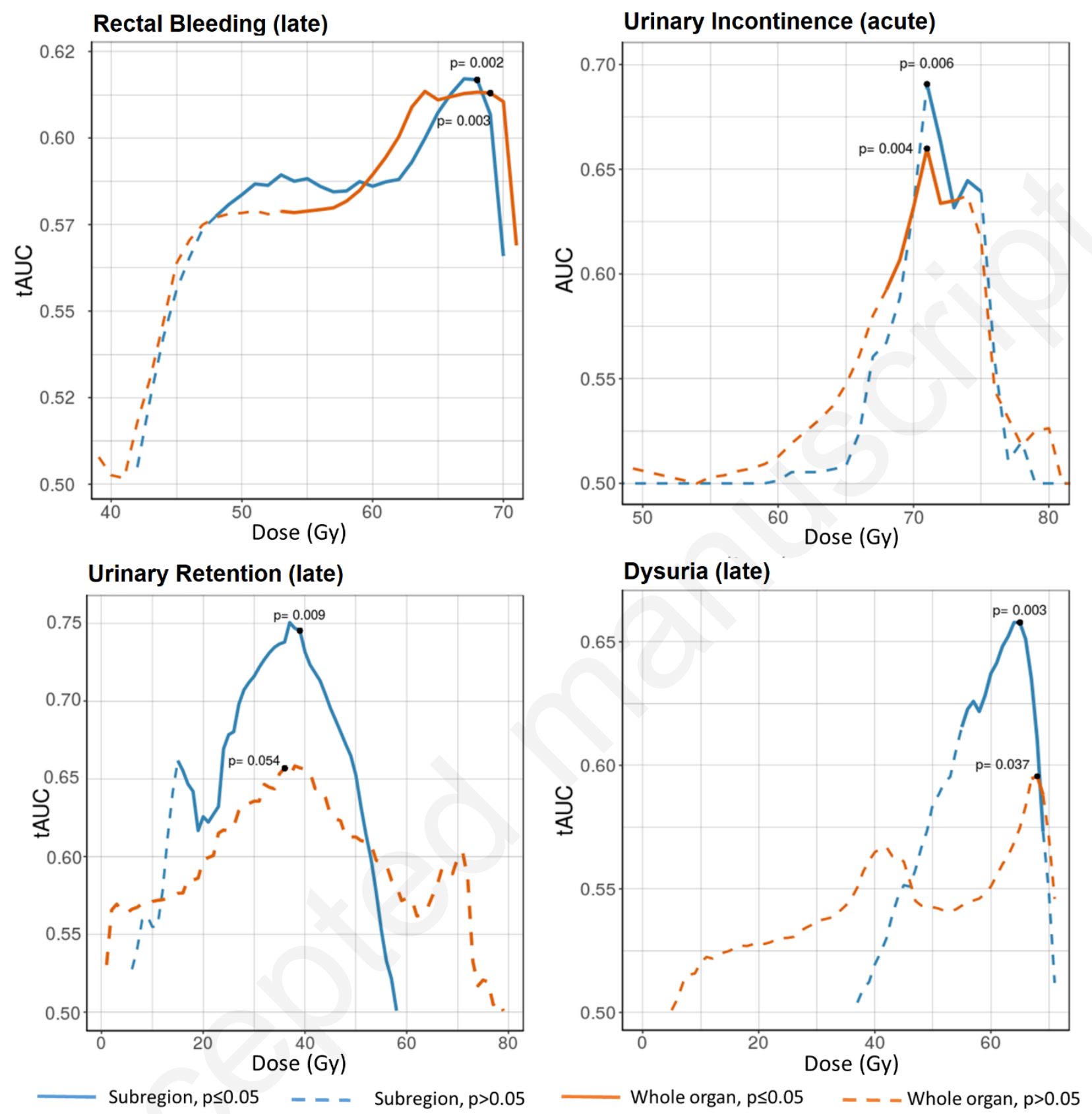

Figure 4. Bin-wise grade $\geq 2$ discriminatory power of the DVHs for the subregions and the whole organs

Logistic regression was used to compute the discriminatory power of the DVH for acute toxicity (incontinence) and Cox regression for late toxicity (rectal bleeding, dysuria and hematuria). X-axis represents the dose level $(x)$ corresponding to the volume $(\mathrm{V} x)$ of the DVH. Continuous and dashed lines represent the $p$-values $\leq 0.05$ and $p$-values $>0.05$, respectively. Blue and orange lines represent the discriminatory power of the DVH in the subregions and the whole organs (bladder/rectum), respectively. 